\title{
Dysmagnesaemia and outcome in a trauma ICU
}

\author{
J Ilicki, ${ }^{1}$ MD; T C Hardcastle, ${ }^{2}$ MB ChB, MMed (Chir), FCS (SA), PhD; H Barle, ${ }^{1}$ MD, PhD; \\ D J J Muckart, ${ }^{2}$ MB ChB, MMed Sci, FRCS, ACS (SA) Crit Care \\ ${ }^{1}$ Karolinska Institute, Stockholm, Sweden \\ ${ }^{2}$ Inkosi Albert Luthuli Central Hospital Trauma Service, Durban, KwaZulu-Natal, South Africa
}

Corresponding author: TC Hardcastle (hardcastle@ukzn.ac.za or timothyhar@ialch.co.za)

\begin{abstract}
Objective. To determine the prevalence of dysmagnesaemia among patients admitted to a trauma intensive care unit (ICU) and to investigate whether dysmagnesaemia at admission correlated with a worse outcome.

Methods. In this retrospective case study of patients admitted to a regional level 1 trauma unit, from April 2007 to November 2010 , de-identified patient data were obtained from the local patient database. Patients were divided into three groups (hypomagnesaemic, normomagnesaemic and hypermagnesaemic), which in turn were divided into two subgroups (blunt and penetrating trauma). The mortality between normo- and hypomagnesaemic patients, as well as between the subgroups, was analysed using $\chi^{2}$ tests. The University of KwaZulu-Natal Biomedical Research Ethics Committee approved the study (BE207/09).

Results. Of the 759 trauma patients studied, $10.7 \%$ were hypomagnesaemic and $1.3 \%$ were hypermagnesaemic at admission. No statistically significant difference in mortality was observed between the hypo- and normo-/hypermagnesaemic patients.

Conclusion. Dysmagnesaemia is common among trauma patients admitted to the ICU, but is not necessarily correlated with a poorer outcome.
\end{abstract}

S Afr J Crit Care 2014;30(2):45-50. DOI:10.7196/SAJCC.190

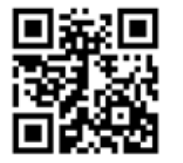

Magnesium ( $\mathrm{Mg})$ is a common mineral salt in the human body, being the second most prevalent intracellular cation, the majority of which is concentrated in bone, muscle and soft tissue. It is essential for over 300 enzymatic reactions and is a prerequisite for human life. ${ }^{[1-4]}$ The main absorption of Mg occurs in the jejunum and ileum, while the kidneys have an important homeostatic role. ${ }^{[5]}$

Over $99 \%$ of body Mg is in the intracellular space. Ninety per cent of this intracellular Mg is bound to adenosine triphosphate, cytoskeleton nucleotides and enzymes, whereas the rest is ionised and unbound within the cell. ${ }^{[3]}$ In serum, $\mathrm{Mg}$ is either ionised (80\%) or bound to proteins (20\%). ${ }^{[1]}$ Since only $1 \%$ of body $\mathrm{Mg}$ is contained in serum, both ionised $\mathrm{Mg}(\mathrm{iMg})$ and total serum $\mathrm{Mg}(\mathrm{tMg})$ are poor indicators of total body Mg content. Consequently, hypomagnesaemia in serum can occur when total body content is normal or low. ${ }^{[6,7]}$

Serum hypomagnesaemia is associated with several pathologies, ranging from arrhythmias and pre-eclampsia to cerebral ischaemia. ${ }^{[2,8]}$ Its correlation with outcome among critically ill patients has been studied and varies greatly (Table 1). ${ }^{[9-19]}$ Some studies have found an increased mortality associated with admission hypomagnesaemia, ${ }^{[11,12,17]}$ admission hypermagnesaemia, ${ }^{[1,1,13,17]}$ the development of hypomagnesmia, ${ }^{[18]}$ and the development of hypermagnesaemia; ${ }^{[6]}$ while others have found no correlation at all. ${ }^{[16,19]}$ Similarly, the prevalence of admission hypomagnesaemia varies greatly among studies and, according to one report, is more common among trauma patients. ${ }^{[7]}$

It is still unclear, therefore, whether or not dysmagnesaemia is correlated with a worse outcome in critically ill patients. The objective of this retrospective study was to investigate the prevalence of dysmagnesaemia among patients admitted to a level 1 (Trauma Society of South Africa criteria) trauma intensive care unit (ICU) and to determine if dysmagnesaemia is associated with worse outcome.

\section{Methods}

The trauma ICU at the Inkosi Albert Luthuli Central Hospital (IALCH), Durban, a major regional referral hospital, is a level 1 trauma centre, including an integrated ICU unit. The unit has eight ICU beds and eight high-care beds, and admits both adult and paediatric patients above the age of 2 years. The functioning and referral process of the unit have been previously described.$^{[20]}$ Aminoglycosides are not used in the unit antibiotic protocols as a parenteral therapy.

After obtaining approval from the University of KwaZulu-Natal Biomedical Research Ethics Committee (BE207/09), data were extracted from the Medicom databank for patients admitted to the trauma ICU from April 2007 to November 2010. All patients who had an admission $\mathrm{Mg}$ level measured within $24 \mathrm{~h}$ were included, while patients were excluded if their trauma was not typical penetrating or blunt injury. The data captured included age, sex, mechanism of trauma, Injury Severity Score (ISS), New Injury Severity Score (NISS), duration of stay at the ICU $\left(I C U_{\text {stay }}\right)$, if the patient was operated on, outcome, creatinine levels at admission, iMg levels at admission $\left(\mathrm{iMg} \mathrm{gdm}_{\mathrm{am}}\right.$ ), and maximum iMg ( $\left(\mathrm{Mg}_{\max }\right)$ and minimum iMg ( $\mathrm{iMg}_{\min }$ ) levels.

The local sampling technique utilised was as follows: Within $24 \mathrm{~h}$ of admission, a peripheral blood sample was collected in a $5 \mathrm{~mL}$ Vacuette serum tube (article no. 456073p; Grener Bio-One, Germany). The samples were centrifuged at $2000 \mathrm{G}$ at room temperature for $10 \mathrm{~min}$, transferred to a plain tube and then analysed using the ADVIA 1800 chemistry system (Siemens, Germany). The ADVIA 1800 utilises a reaction between $\mathrm{Mg}$ and $\mathrm{xylidyl}$ blue, which creates a watersoluble complex that can be measured by spectrophotometry. The complex created is proportional to the $\mathrm{Mg}$ in the sample, therefore the $\mathrm{Mg}$ concentration is quantified by measuring absorbance at the 
Table 1. Prevalence of dysmagnesaemia in the ICU setting: publication comparison

\begin{tabular}{|c|c|c|c|c|c|c|c|c|}
\hline \multicolumn{2}{|l|}{ Study } & \multirow[b]{2}{*}{ ICU type } & \multirow{2}{*}{$\begin{array}{l}\text { Patients, } \\
n\end{array}$} & \multirow[b]{2}{*}{ Measure } & \multirow{2}{*}{$\begin{array}{l}\text { Mg normal } \\
\text { range (mmol/L) }\end{array}$} & \multicolumn{2}{|c|}{ Admission } & \multirow{2}{*}{$\begin{array}{l}\text { Association between } \\
\text { mortality and ... }\end{array}$} \\
\hline Author, year & Type & & & & & Hypo-Mg (\%) & Hyper-Mg (\%) & \\
\hline Ryzen, 1985 & Pros & Med & 94 & $\mathrm{tMg}$ & * & 65 & * & No association reported \\
\hline Reinhart, 1985 & Pros & Med & 102 & $\mathrm{tMg}$ & $0.70-1.00$ & 20 & 9 & No association reported \\
\hline Chernow, 1989 & Pros & Postop & 193 & $\mathrm{tMg}$ & $0.75-1.00$ & 61 & 5 & Hypo/hyper-Mg \\
\hline Rubeiz, 1993 & Pros & $\begin{array}{l}\text { Mixed med } \\
\text { ICU/ward }\end{array}$ & 381 & $\mathrm{tMg}$ & $0.62-1.07$ & 19 & 3.5 & Hypo-Mg \\
\hline Guérin, 1996 & Pros & Med & 179 & $\mathrm{tMg}$ & $0.75-1.00$ & 44 & 6 & Hyper-Mg \\
\hline \multirow[t]{2}{*}{ Fiser, 1998} & Pros & Paed & 67 & $\mathrm{iMg}$ & $0.40-*$ & 59 & * & No association reported \\
\hline & & & & $\mathrm{tMg}$ & $0.71-1.00$ & $*$ & & \\
\hline \multirow[t]{2}{*}{ Frankel, 1999} & Pros & Trauma & 113 & $\mathrm{iMg}$ & $0.21-*$ & 4 & * & No association reported \\
\hline & & & & $\mathrm{tMg}$ & $0.75-1.01$ & 51 & & \\
\hline Huijgen, 2000 & Pros & Multi & 115 & $\mathrm{iMg}$ & $0.47-0.65$ & 14 & * & None (epiphenomenon) \\
\hline Singhi, 2003 & Pros & Paed & 100 & $\mathrm{tMg}$ & $0.70-1.00$ & 60 & 4 & Hypo/hyper-Mg \\
\hline Soliman, 2003 & Pros & Med-surg & 446 & $\mathrm{iMg}$ & $0.42-0.59$ & 18 & 14 & $\begin{array}{l}\text { Developing ionised } \\
\text { hypo-Mg }\end{array}$ \\
\hline & & & & $\mathrm{tMg}$ & $0.75-0.95$ & 52.5 & 13.5 & Developing ionised \\
\hline Escuela, 2005 & Pros & - & 144 & $\mathrm{iMg}$ & $0.44-0.60$ & 9.7 & 23.6 & hyper-Mg \\
\hline Saleem, 2009 & Retr & Paed & 179 & $\mathrm{tMg}$ & $0.95-*$ & 44 & * & No association reported \\
\hline
\end{tabular}

complex's wavelength (505- $694 \mathrm{~nm})$. The normal range for iMg using the ADVIA 1800 is $0.53-1.11 \mathrm{mmol} / \mathrm{L}$, which is based on the manufacturer's own specifications.

Mg supplementation was undertaken on indication, such that any patient with an $\mathrm{iMg}$ $<0.7 \mathrm{mmol} / \mathrm{L}$ at $24 \mathrm{~h}$ after admission was followed up with repeated measurements of serum $\mathrm{Mg}$. If $\mathrm{iMg}$ remained $<0.7 \mathrm{mmol} / \mathrm{L}$ at $48 \mathrm{~h}$ following admission, standard $\mathrm{Mg}$ supplementation was repeatedly given until iMg was $\geq 0.7 \mathrm{mmol} / \mathrm{L}$. Supplementation comprised $2 \mathrm{~g} \mathrm{MgSO}_{4}$ diluted in $50 \mathrm{~mL}$ physiologic saline, given at least once daily over $1 \mathrm{~h}$. The dose was repeated in cases of severely low values up to three times per day, as empirical treatment. ${ }^{[2]}$

Statistical analysis was performed using GraphPad (Graphpad Software La Jolla, USA). The collected data were analysed using an unpaired Student's $t$-test, $\chi^{2}$ tests and logistical regression analysis. The patients were stratified into three groups depending on their $\mathrm{Mg}$ level at admission: group A included hypomagnesaemic patients, group $B$ included normomagnesaemic patients and group $C$ included hypermagnesaemic patients. Continuous variables (age, ISS, NISS, ICU $\mathrm{CU}_{\text {stay }}$ ) were analysed for each group using means and standard deviations (SDs), and Student's $t$-test. However, as there were so few hypermagnesaemic patients who had died $(n=4)$, group $C$ was combined with group $B$ to allow $\chi^{2}$ testing. The difference in mortality between groups $A$ and $B$ was compared using a $\chi^{2}$ test with one degree of freedom.

Groups A, B and C were divided into two groups depending on the type of trauma. Groups A1, B1 and C1 comprised patients who had suffered blunt trauma, while the victims of penetrating trauma were allocated to groups A2, B2 and C2. Groups $C 1$ and $C 2$ were combined with groups $B 1$ and $B 2$ owing to the low number of patients in group C2 $(n=1)$. Group A and B's mortality was compared using $\chi^{2}$ analysis with three degrees of freedom.

In the normomagnesaemic group, the number of patients who developed dysmagnesaemia during their ICU stay was calculated and group mortality was analysed using $\chi^{2}$ analysis with five degrees of freedom. Linear regression analyses were performed to explore an eventual correlation between NISS, Mg level and outcome.

\section{Results}

The databank contained data for a total of 822 patients from April 2007 to November 2010. Of these, 761 were initially reviewed, as their iMg was measured at admission.
Table 2. Trauma diagnosis

\begin{tabular}{ll}
\hline Diagnosis & $n(\%)$ \\
\hline Blunt trauma & $547(72.1)$ \\
Motor vehicle accident & $472(62.2)$ \\
Blunt trauma & $75(9.9)$ \\
Penetrating trauma & $212(27.9)$ \\
Gunshot wounds & $135(10.1)$ \\
Stab wounds & $77(17.8)$ \\
Total & $759(100)$
\end{tabular}

Two cases were subsequently excluded since they were not victims of either blunt or penetrating trauma (admission after snake bite and drowning). For the remaining 759 patients, complete demographic data were recorded and analysed.

A total of $74 \%(n=564)$ of the patients were male (male:female ratio 3:1) with the mean age 30 years (median 28). Seventy-five per cent $(n=570)$ of the patients came as referrals from other hospitals, of whom $24 \%(n=140)$ had undergone surgery; the remaining $25 \%$ came directly from the scene of trauma. None of the patients was admitted to an ICU at the referring hospitals; only urgent lifesaving surgery had been performed there prior to transfer to IALCH. Mean length of stay was 13 (SD 14) days (median 9, mode 2). 
Table 3. Demographics, $N=759$

\begin{tabular}{|c|c|c|c|c|}
\hline & \multicolumn{4}{|c|}{ Mean (SD; range) } \\
\hline & Total & $\mathrm{iMg}_{\mathrm{adm}}<0.53 \mathrm{mmol} / \mathrm{L}$ & $0.53 \leq \mathrm{iMG}_{\mathrm{adm}}<1.11 \mathrm{mmol} / \mathrm{L}$ & $\mathrm{iMg}_{\mathrm{adm}} \geq 1.11 \mathrm{mmol} / \mathrm{L}$ \\
\hline Age (years) & $30(15 ; 1-83)$ & $30.5(10.2 ; 14-67)$ & $29.3(15.6 ; 1-83)$ & $33.4(21.0 ; 2-78)$ \\
\hline ISS (points) & $23(13 ; 1-75)$ & $24.6(13.5 ; 9-75)$ & $23.2(13.4 ; 1-75)$ & $16.6(11.4 ; 4-38)$ \\
\hline NISS (points) & $29(15 ; 1-75)$ & $33.2(15.2 ; 9-75)$ & $28.9(15.1 ; 1-75)$ & $20.7(12.3 ; 8-50)$ \\
\hline \multirow[t]{2}{*}{ Stay in ICU (days) } & $13(14 ; 0-108)$ & $11.3(10.2 ; 0-54)$ & $13.1(14.7 ; 0-108)$ & $10.1(8.6 ; 0-28)$ \\
\hline & \multicolumn{4}{|c|}{$n(\%)$} \\
\hline All patients & $759(100)$ & $81(10.7)$ & $668(88.0)$ & $10(1.3)$ \\
\hline Survivors & $591(78.0)$ & $57(70.4)$ & $528(79.0)$ & $6(60.0)$ \\
\hline
\end{tabular}

Table 4. Dysmagnesaemia at admission, trauma type and outcome

\begin{tabular}{|c|c|c|c|c|c|c|}
\hline \multirow[b]{2}{*}{ Trauma } & \multicolumn{2}{|c|}{$\mathrm{iMg}<0.53 \mathrm{mmol} / \mathrm{L}$} & \multicolumn{2}{|c|}{$0.53 \leq \mathrm{iMg}<1.11 \mathrm{mmol} / \mathrm{L}$} & \multicolumn{2}{|c|}{ iMg $\geq 1.11 \mathrm{mmol} / \mathrm{L}$} \\
\hline & Blunt & Penetrating & Blunt & Penetrating & Blunt & Penetrating \\
\hline Group & $\mathrm{A} 1$ & $\mathrm{~A} 2$ & B1 & B2 & $\mathrm{C} 1$ & $\mathrm{C} 2$ \\
\hline Patients, $n$ (\% total) & $44(5.8)$ & $37(4.9)$ & $494(65.1)$ & $174(22.9)$ & $9(1.2)$ & $1(0.1)$ \\
\hline Survivors $n$ (\% group) & $29(65.9)$ & $28(75.7)$ & $390(78.9)$ & $138(79.3)$ & $6(66.7)$ & $0(0)$ \\
\hline
\end{tabular}

Table 5. Dysmagnesaemia and patients grouped by NISS score

\begin{tabular}{|c|c|c|c|c|c|c|}
\hline NISS & $\begin{array}{l}\text { Patients, \% } \\
(n)\end{array}$ & $\begin{array}{l}\mathbf{i M g}_{\text {adm }^{\prime}} \\
\text { mean (SD) }\end{array}$ & $\begin{array}{l}\text { Hypo patients } \\
\%(n)\end{array}$ & $\begin{array}{l}\text { Normo patients, } \\
\%(n)\end{array}$ & $\begin{array}{l}\text { Hyper patients, } \\
\%(n)\end{array}$ & $\begin{array}{l}\text { Survivors, \% } \\
\text { (n) }\end{array}$ \\
\hline$<25$ & $37.9(288)$ & $0.73(0.14)$ & $9.0(26)$ & $88.9(256)$ & $2.1(6)$ & $90.6(261)$ \\
\hline $25-50$ & $55.2(419)$ & $0.70(0.16)$ & $10.7(45)$ & $88.3(370)$ & $0.95(4)$ & 74.9 (314) \\
\hline$>50$ & $6.9(52)$ & $0.68(0.15)$ & $19.2(10)$ & $80.5(42)$ & $0(0)$ & $30.8(16)$ \\
\hline
\end{tabular}

Sixty-two per cent $(n=467)$ of the patients were operated on after admission. Overall, $78 \%$ of the patients survived their stay in the ICU. The population's diagnoses are illustrated in Table 2 and their demographic data are outlined in Table 3.

A Student's $t$-test exposed no statistically significant difference in the groups' age or duration of stay in the ICU. However, there were statistically significant differences between the groups' NISS scores $(p<0.02$ comparing hypo- and normomagnesaemic patients; $p<0.05$ comparing normo- and hypermagnesaemic patients; $p<0.005$ comparing hypo- and hypermagnesaemic patients). Moreover, a statistically significant difference was found to exist between the ISS scores of the hypo- and hypermagnesaemic patients $(p<0.05)$.

The group of hypermagnesaemic patients who died was too small $(n=4)$ to allow $\chi^{2}$ testing of a mortality difference. Consequently, the hyper- and normomagnesaemic

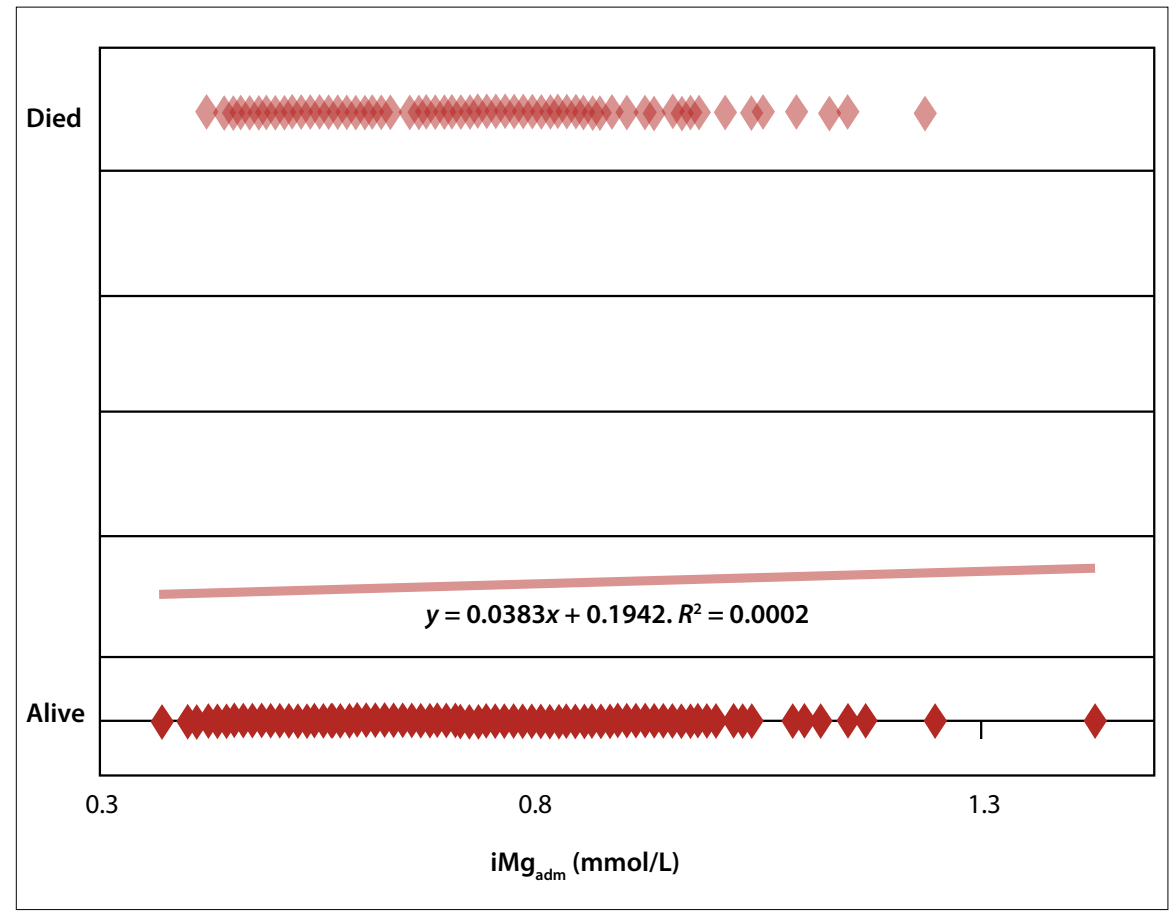

Fig. 1. $i \mathrm{Mg}_{\text {adm }}$ and outcome. ( $\mathrm{iMg} \mathrm{g}_{\text {adm }}=$ ionised magnesium levels at admission.) 


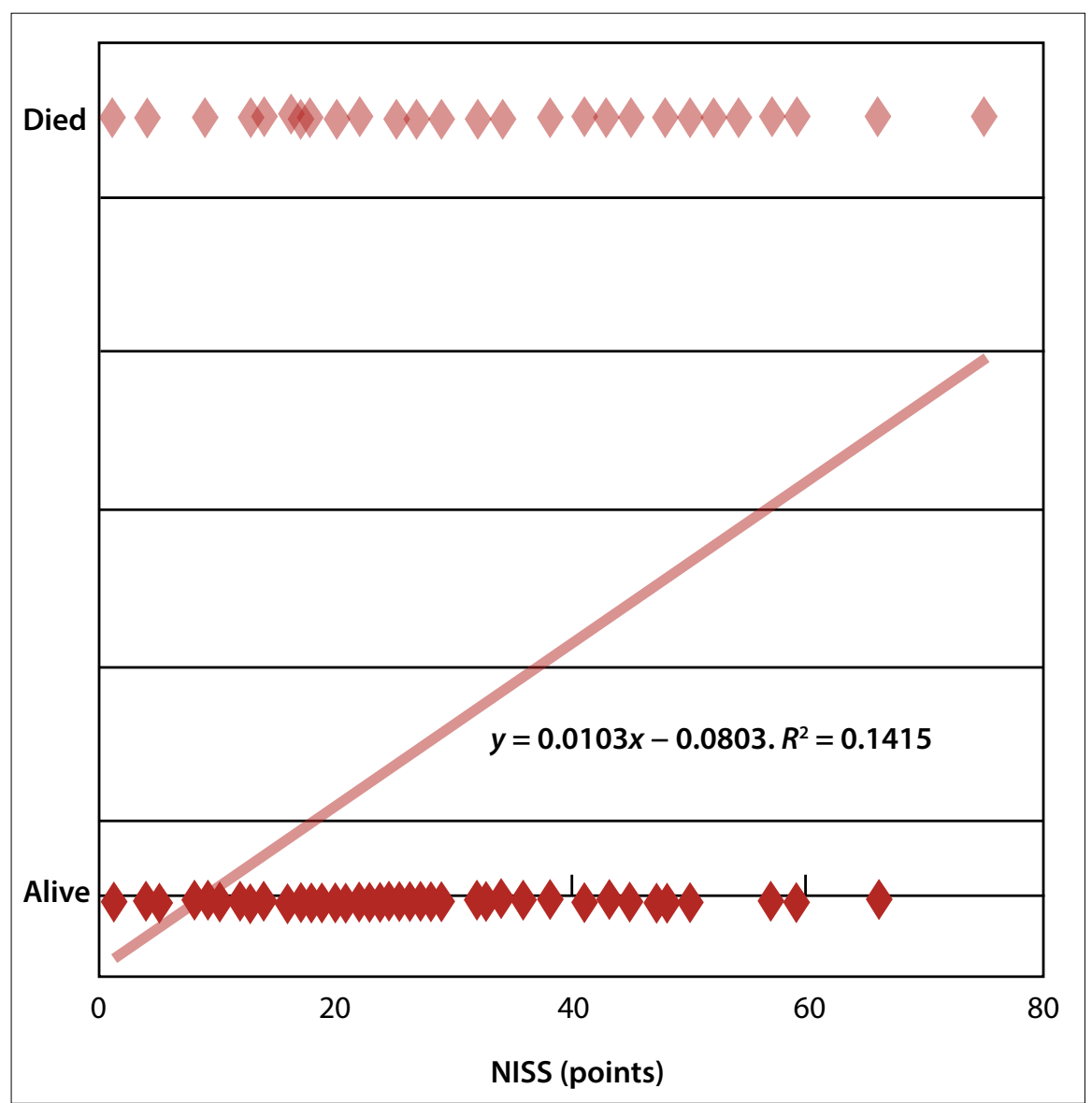

Fig. 2. NISS and outcome. (NISS = New Injury Severity Score.)

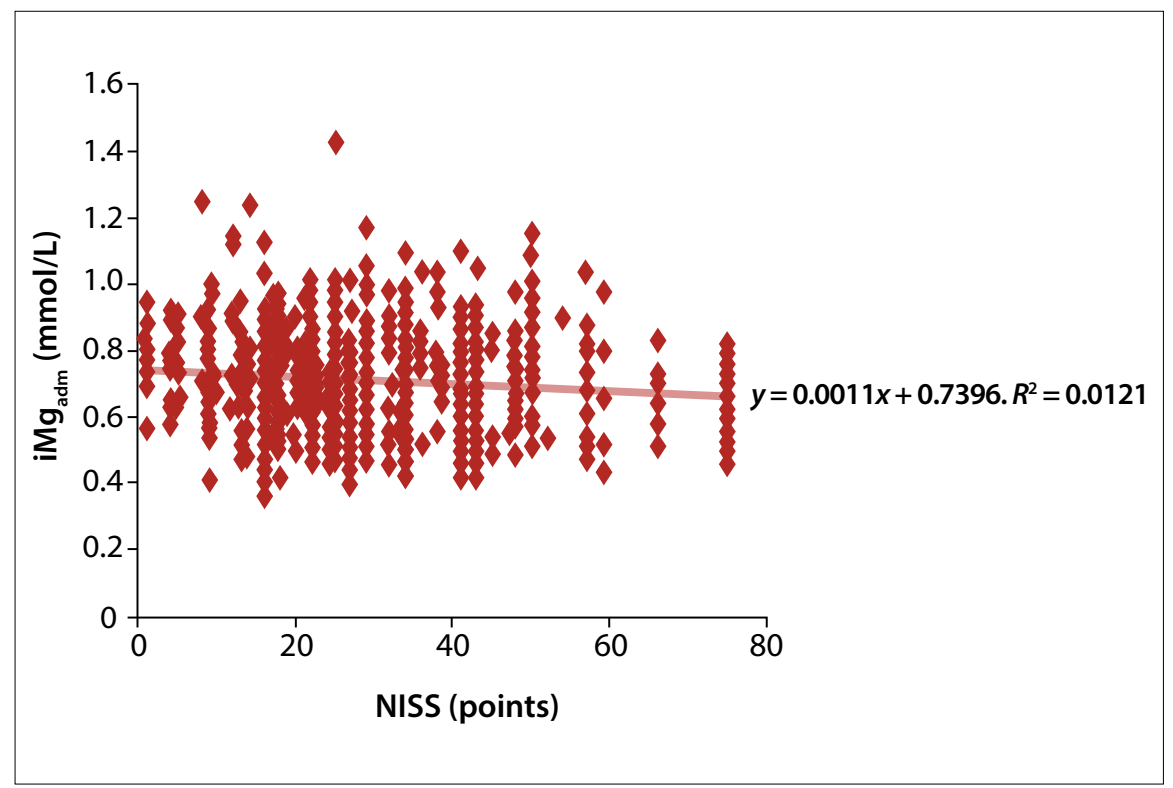

Fig. 3. NISS and $i \mathrm{Mg}_{\text {adm. }}$ (NISS = New Injury Severity Score; $i \mathrm{Mg}_{\text {adm }}=$ ionised magnesium levels at admission.)

patients were grouped together and their mortality was compared with that of the hypomagnesaemic patients. A $\chi^{2}$ test with one degree of freedom did not find a statistically significant difference in mortality between the groups $\left(\chi^{2}=2.96\right)$. degrees of freedom, revealed no statistically significant difference $\left(\chi^{2}=4.02\right)$.

The patients were divided into three groups depending on their NISS score (Table 5). For each group, the percentage that survived, and the mean iMg and SD were calculated, as well as the percentage of each group that was hypo-, normo- or hypermagnesaemic. Three linear regression analyses were performed to evaluate possible correlations between $\mathrm{iMg}_{\text {adm }}$ NISS score and outcome. These did not find any correlations (Figs 1, 2 and 3).

In order to evaluate if the development of dysmagnesaemia was associated with a poorer prognosis, the patient data were grouped as illustrated in Table 6. A $\chi^{2}$ test was performed, but in order to avoid too-small groups $(n<5)$, all patients who had developed both hypo- and hypermagnesaemia were grouped together with the patients who had only developed hypomagnesaemia. A $\chi^{2}$ test with five degrees of freedom yielded a result of $x^{2}=2.60$, thus showing that there was no difference in mortality between the patients who remained normomagnesaemic or those who became dysmagnesaemic.

The data were re-evaluated using a narrower interval of normal $\mathrm{Mg}(0.44$ $0.60 \mathrm{mmol} / \mathrm{L}$ ) (Table 7). Admission serum creatinine ( $\left(\mathrm{Crea}_{\mathrm{adm}}\right)$ is illustrated in Table 8 for the hypo-, normo- and hypermagnesaemic patients. Overall, 34 patients in the RIFLE I group developed acute kidney injury during ICU admission, and in none of these was a link with the subsequent development of hypomagnesaemia noted, despite there being admission hypomagnesaemia present in some of them.

\section{Discussion}

The findings in this study of ionised hypomagnesaemia at admission are in concordance with those of Escuela et al., ${ }^{[7]}$ who found a prevalence of $9.7 \%$. However, other studies have found a prevalence of ionised hypomagnesaemia of between $14 \%$ and $59 \%$. These differences can be explained by dissimilar normal ranges for $\mathrm{Mg}$ (a lower limit of $0.47,0.42,0.21$ and $0.40 \mathrm{mmol} / \mathrm{L}$, respectively), different populations (multicentre ICU, medical-surgical ICU, trauma ICU and paediatric ICU) and varied laboratory methods (different ion selective electrodes such as KONE, NOVA SP9 and NOVA 8).

The prevalence of hypermagnesaemia at admission (1.3\%) in this trauma population was markedly lower than any 
Table 6. Outcome among normomagnesaemic patients developing dysmagnesaemia

\begin{tabular}{|c|c|c|c|}
\hline Group & Became ... during ICU stay & Total patients, \% (n) & Survivors, \% (n) \\
\hline \multirow[t]{4}{*}{ B1 } & Hypomagnesaemic* & $3.8(29)$ & $75.9(22)$ \\
\hline & Normomagnesaemic ${ }^{\dagger}$ & $56.1(426)$ & $80.3(342)$ \\
\hline & Hypermagnesaemic ${ }^{\ddagger}$ & $4.3(33)$ & $66.7(22)$ \\
\hline & Hypo- and hypermagnesaemic & $0.8(6)$ & $66.7(4)$ \\
\hline \multirow[t]{4}{*}{ B2 } & Hypomagnesaemic* & $1.8(14)$ & $78.6(11)$ \\
\hline & Normomagnesaemic ${ }^{\dagger}$ & $17.8(135)$ & $84.4(114)$ \\
\hline & Hypermagnesaemic ${ }^{\ddagger}$ & $2.4(18)$ & $50.0(9)$ \\
\hline & Hypo- and hypermagnesaemic & $0.9(7)$ & $57.1(4)$ \\
\hline \multicolumn{4}{|c|}{$\mathrm{ICU}=$ intensive care unit; $\mathrm{iMg}_{\min }=$ minimum ionised magnesium; $\mathrm{iMg}_{\max }=$ maximum ionised magnesium. } \\
\hline \multicolumn{4}{|c|}{ *Hypomagnesaemia: $\mathrm{iMg}_{\min }<0.53}$. \\
\hline \multicolumn{4}{|c|}{${ }^{\dagger}$ Normomagnesaemia: $\mathrm{iMg}_{\min } \geq 0.53$ and $\mathrm{iMg}_{\max }<1.11$} \\
\hline \multicolumn{4}{|c|}{ "Hypermagnesaemia: $\mathrm{iMg}_{\max } \geq 1.11$. } \\
\hline
\end{tabular}

Table 7. Analysis with normal range of $0.44-0.60 \mathrm{mmol} / \mathrm{L}, \mathrm{N}=759$

\begin{tabular}{|c|c|c|c|c|}
\hline & Total & $\begin{array}{l}\mathrm{iMg}_{\mathrm{adm}}<0.44 \\
\mathrm{mmol} / \mathrm{L}\end{array}$ & $\begin{array}{l}0.44 \leq \mathrm{iMg}_{\mathrm{adm}}<0.60 \\
\mathrm{mmol} / \mathrm{L}\end{array}$ & $\begin{array}{l}\mathrm{iMg}_{\mathrm{adm}} \geq 0.60 \\
\mathrm{mmol} / \mathrm{L}\end{array}$ \\
\hline Total patients, $\%(n)$ & 100 (759) & $1.1(8)$ & $25.2(191)$ & $73.8(560)$ \\
\hline Survivors, \% (n) & $78(591)$ & $75.0(6)$ & $75.0(144)$ & $78.8(441)$ \\
\hline
\end{tabular}

Table 8. Creatinine and dysmagnesaemia

\begin{tabular}{|c|c|c|c|c|c|}
\hline \multirow[b]{2}{*}{ Mg } & \multirow[b]{2}{*}{$\begin{array}{l}\text { Total patients, } \\
\%(n)\end{array}$} & \multicolumn{4}{|c|}{ Patient group, \% (n) } \\
\hline & & $\begin{array}{l}<100 \\
\mu \mathrm{mol} / \mathrm{L}\end{array}$ & $\begin{array}{l}100 \text { - } 149 \\
\mu \mathrm{mol} / \mathrm{L}\end{array}$ & $\begin{array}{l}150-200 \\
\mu \mathrm{mol} / \mathrm{L}\end{array}$ & $\begin{array}{l}>200 \\
\mu \mathrm{mol} / \mathrm{L}\end{array}$ \\
\hline$<0.53$ & $10.7(81)$ & $77.8(63)$ & $17.3(14)$ & $1.2(1)$ & $3.7(3)$ \\
\hline $0.53-1.11$ & $88.0(666)$ & 72.7 (484) & $18.8(125)$ & $3.8(25)$ & $4.8(32)$ \\
\hline$>1.11$ & $1.3(10)$ & $10(1)$ & $40(4)$ & $0(0)$ & $50(5)$ \\
\hline
\end{tabular}

other reported in the literature $(14 \%$ and 23.6\%). ${ }^{[7,18]}$ A possible explanation is that the normal range used for $\mathrm{Mg}$ is broader than that in other studies $(0.53-1.11$ compared with $0.42-0.59$ and $0.44-0.60$ $\mathrm{mmol} / \mathrm{L})^{[7,18]}$ However, re-analysing these study data with a normal $\mathrm{iMg}$ interval of $0.44-0.60 \mathrm{mmol} / \mathrm{L}$ also yielded dissimilar results. The laboratory method used locally, namely spectrophotometry, could potentially give less-accurate values than the ion-selective electrodes used in other studies, thus explaining the need for a broader normal interval, as well as a difference in admission dysmagnesaemia that cannot be corrected using a different normal interval.

estasis, not finding a correlation simply mean that confounding factors have not been controlled appropriately, which is probable in a retrospective study of this nature, despite using an electronic patient record system.

\section{Study limitations}

Firstly, patients were not excluded when using aminoglycosides and diuretics, or if they developed renal failure (RF). However, in the trauma ICU, aminoglycosides may be used, though rarely before $72 \mathrm{~h}$ after admission and usually for durations limited to $24 \mathrm{~h}$, since it has been shown that tissue levels are not adequate in the acute trauma phase. ${ }^{[22]}$ Other studies have excluded patients with chronic RF, as this can cause dysmagnesaemia. ${ }^{[5,6]}$ We did not exclude patients who may have developed acute kidney injury, since we were interested to see if dysmagnesaemia, irrespective of the cause, was related to outcome. Moreover, as seen in Table 8, the vast majority of the patients with hypomagnesaemia had a Crea $_{\text {adm }}$ of $<100 \mu \mathrm{mol} / \mathrm{L}$ (normal range 0 - $80 \mu \mathrm{mol} / \mathrm{L})$. However, most patients with hypermagnesaemia had a $\mathrm{Crea}_{\mathrm{adm}}$ of $100-149 \mu \mathrm{mol} / \mathrm{L}$ or $>200 \mu \mathrm{mol} / \mathrm{L}$. Consequently, RF may be a confounding variable when exploring the outcome for the hypermagnesaemic patients.

Secondly, all patients had suffered multiple injuries and had typically received transfusion of fluids not containing Mg, causing haemodilution, and would typically have high serum catecholamine levels, which have been shown to cause $\mathrm{Mg}$ shift to the intracellular space. ${ }^{[5]}$ Moreover, acidosis is known to be able to shift $\mathrm{Mg}^{2+}$ into the urine. ${ }^{[2]}$ Of the 759 patients included in this study, 663 had serum lactate measured at admission. Of these 663 patients, 274 had lactate levels $>2.3 \mathrm{mmol} / \mathrm{L}$ (mean 4.0, median 2.7, mode 1.3), a marker of severe metabolic acidosis after acute injury. There remain, therefore, several confounding factors that could not have been controlled when analysing the data.

\section{Conclusion}

Of the patients admitted to the trauma ICU, $10.7 \%$ were hypomagnesaemic, while $1.3 \%$ were hypermagnesaemic. No correlation was found between hypomagnesaemia and a poorer outcome, despite some association with patients who had a higher ISS or NISS. $\mathrm{Mg}$ supplementation may be beneficial in the ICU, but this study was not powered to prove the effect of this intervention on patient outcome.
Acknowledgements. The authors wish to thank Hannes Malmberg for his assistance with data analysis and statistics. 


\section{References}

1. Martin KJ, González EA, Slatopolsky E. Clinical consequences and management of hypomagnesaemia. J Am Soc Nephrol 2009;20(11):2291-2295. [http://dx.doi.org/10.1681/ ASN.2007111194]

2. Tong GM, Rude RK. Magnesium deficiency in critical illness. J Intensive Care Med 2005;20(1):317. [http://dx.doi.org/10.1177/0885066604271539]

3. Dubé L, Granry JC. The therapeutic use of magnesium in anesthesiology, intensive care and emergency medicine: A review. Can J Anaesth 2003;50(7):732-746. [http://dx.doi.org/10.1007/ BF03018719]

4. Buckley MS, Leblanc JM, Cawley MJ. Electrolyte disturbances associated with commonly prescribed medications in the intensive care unit. Crit Care Med 2010;38(Suppl 6):S253-264. prescribed medications in the intensive care unit. Crit
[http://dx.doi.org/10.1097/CCM.0b013e3181dda0be]

5. Noronha JL, Matuschak GM. Magnesium in critical illness: Metabolism, assessment, and treatment. Intensive Care Med 2002;28(6):667-679. [http://dx.doi.org/10.1007/s00134-0021281-y]

6. Musso CG. Magnesium metabolism in health and disease. Int Urol Nephrol 2009;41(2):357-362. [http://dx.doi.org/10.1007/s11255-009-9548-7]

7. Escuela MP, Guerra M, Añón JM, et al. Total and ionised serum magnesium in critically ill patients. Intensive Care Med 2005;31(1):151-156. [http://dx.doi.org/10.1007/s00134-004-2508-x]

8. Sen AP, Gulati A. Use of magnesium in traumatic brain injury. Neurotherapeutics 2010;7(1):9199. [http://dx.doi.org/10.1016/j.nurt.2009.10.014]

9. Ryzen E, Wagers PW, Singer FR, Rude RK. Magnesium deficiency in a medical ICU population. Crit Care Med 1985;13(1):19-21.

10. Reinhart RA, Desbiens NA. Hypomagnesaemia in patients entering the ICU. Crit Care Med 1985;13(6):506-507.

11. Chernow B, Bamberger $S$, Stoiko $M$, et al. Hypomagnesaemia in patients in postoperative intensive care. Chest 1989;95(2):391-397.
12. Rubeiz GJ, Thill-Baharozian $M$, Hardie $D$, Carlson RW. Association of hypomagnesaemia and mortality in acutely ill medical patients. Crit Care Med 1993;21(2):203-209.

13. Guérin C, Cousin C, Mignot F, Manchon M, Fournier G. Serum and erythrocyte magnesium in critically ill patients. Intensive Care Med 1996;22(8):724-727.

14. Fiser RT, Torres A Jr, Butch AW, Valentine JL. Ionised magnesium concentrations in critically ill children. Crit Care Med 1998;26(12):2048-2052.

15. Frankel $H$, Haskell R, Lee SY, Miller D, Rotondo M, Schwab CW. Hypomagnesaemia in trauma patients. World J Surg 1999;23(9):966-969.

16. Huijgen HJ, Soesan M, Sanders R, Mairuhu WM, Kesecioglu J, Sanders GT. Magnesium levels in critically ill patients. What should we measure? Am J Clin Pathol 2000;114(5):688-695.

17. Singhi SC, Singh J, Prasad R. Hypo- and hypermagnesaemia in an Indian pediatric intensive care unit. Journal of Tropical Pediatrics 2003;49(2):99-103. [http://dx.doi.org/10.1093/ tropej/49.2.99]

18. Soliman HM, Mercan D, Lobo SS, Mélot C, Vincent JL. Development of ionised hypomagnesaemia is associated with higher mortality rates. Crit Care Med 2003;31(4):1082-1087.

19. Haque A, Saleem AF. On admission hypomagnesaemia in critically ill children: Risk factors and outcome. Indian J Pediatr 2009;76(12):1227-1230. [http://dx.doi.org/10.1007/s12098009-0258-z]

20. Cheddie S, Muckart DJJ, Hardcastle TC, Den Hollander D, Cassimjee H, Moodley S. An audit of a new level 1 Trauma Unit in urban KwaZulu-Natal. S Afr Med J 2011;101:176-178.

21. Lee JW. Fluid and electrolyte disturbances in critically ill patients. Electrolyte Blood Press 2010;8(2):72-81. [http://dx.doi.org/10.5049/EBP.2010.8.2.72]

22. Goldberg SR, Anand RJ, Como JJ, et al. Prophylactic antibiotic use in penetrating abdominal trauma: An Eastern Association for the Surgery of Trauma practice management guideline. J Trauma 2012;73(5):S321-S325. [http://dx.doi.org/10.1097/TA.0b013e3182701902] 